\title{
BMJ Open Exploring patient experiences coping with using multiple medications: a qualitative interview study
}

\author{
Julie C Lauffenburger (10 , , ${ }^{1,2}$ Nancy Haff, ${ }^{1,2}$ Marie E McDonnell, ${ }^{3}$ \\ Daniel H Solomon (D) , ${ }^{4}$ Elliott M Antman, ${ }^{5}$ Robert J Glynn, ${ }^{1,6}$ Niteesh K Choudhry ${ }^{1,2}$
}

To cite: Lauffenburger JC, Haff N, McDonnell ME, et al. Exploring patient experiences coping with using multiple medications: a qualitative interview study. BMJ Open 2021;11:e046860. doi:10.1136/ bmjopen-2020-046860

- Prepublication history and additional supplemental material for this paper are available online. To view these files, please visit the journal online (http://dx.doi.org/10.1136/ bmjopen-2020-046860).

Received 11 November 2020 Accepted 02 November 2021

A Check for updates

(c) Author(s) (or their employer(s)) 2021. Re-use permitted under CC BY-NC. No commercial re-use. See rights and permissions. Published by BMJ.

For numbered affiliations see end of article.

\section{Correspondence to} Dr Julie C Lauffenburger; jlauffenburger@bwh.harvard. edu

\section{ABSTRACT}

Objective Long-term adherence to evidence-based medications in cardiometabolic diseases remains poor, despite extensive efforts to develop and test interventions and deploy clinician performance incentives. The limited success of interventions may be due to ignored factors such as patients' experience of medication-taking. Despite being potentially addressable by clinicians, these factors have not been sufficiently explored, which is particularly important as patients use increasing numbers of medications. The aim is to explore patient perspectives on medication-taking, medication properties that are barriers to adherence, and coping strategies for their medication regimen.

Design Individual, in-person, semistructured qualitative interviews.

Setting Urban healthcare system.

Participants Twenty-six adults taking $\geq 2$ oral medications for diabetes, hypertension or hyperlipidaemia with nonadherence. Interviews were digitally recorded and transcribed. Data were analysed using developed codes to generate themes. Representative quotations were selected to illustrate themes.

Results Participants' mean age was 55 years, 46\% were female and $39 \%$ were non-white. Six key themes were identified: (1) medication-taking viewed as a highly inconvenient action (that patients struggle to remember to do); (2) negative implications because of inconvenience or illness perceptions; (3) actual medication regimens can deviate substantially from prescribed regimens; (4) certain medication properties (especially size and similar appearance with others) may contribute to adherence deviations; (5) development of numerous coping strategies to overcome barriers and (6) suggestions to make medication-taking easier (including reducing drug costs, simplifying regimen or dosing frequency and creating more palatable medications).

Conclusion Patients with poor adherence often find taking prescription medications to be undesirable and take them differently than prescribed in part due to properties of the medications themselves and coping strategies they have developed to overcome medication-taking challenges. Interventions that reduce the inconvenience of medication use and tailor medications to individual needs may be a welcome development.

\section{BACKGROUND}

The underuse of essential medications imposes significant clinical and financial

\section{Strengths and limitations of this study}

- This manuscript elucidates contemporary patient perspectives on medication-taking that have not been sufficiently explored or understood widely by clinicians or healthcare systems.

- We used sound qualitative methods leveraging deep, semistructured qualitative interviews with 26 patients with evidence of non-adherence.

- The primary limitation of this study is that the results are generalisable to the study sample, including notably that participants were non-adherent and were sampled from one geographical location.

burdens on the US healthcare system. ${ }^{1-3}$ Long-term adherence to evidence-based medications, especially in cardiometabolic diseases, remains poor; on average, fewer than half of patients regularly take their prescribed medications. ${ }^{4-6}$ This poor adherence leads to substantial increases in preventable and costly clinical outcomes. ${ }^{17}$

Unfortunately, low rates of adherence have persisted despite extensive efforts to identify and predict patients at risk of poor adherence, develop and test interventions to improve adherence and create incentives for better performance by including adherence as a quality measure. ${ }^{8-12}$ The limited success of prior approaches may be due to other largely ignored factors, such as patients' experiences of medication-taking. ${ }^{813} 14$

Prior literature has suggested that patients may carry substantial negative perceptions about medication-taking that are heavily informed by perceptions of illness from the disease itself or fear of experiencing side effects. ${ }^{1015}$ These views may be further influenced by the inconvenience of obtaining and taking medication regularly, which clinicians or guidelines may not fully appreciate. ${ }^{16}$

Despite being potentially addressable, contemporary patient perspectives on medication-taking have not been sufficiently 
explored, nor understood widely by clinicians or healthcare systems. ${ }^{17-19}$ This is particularly important given that patients are now using increasing numbers of evidencebased medications to reach clinical targets. ${ }^{20-22}$

To this end, we conducted semistructured qualitative interviews with patients to elicit and explore their perceptions of: (1) how they are using their medications and managing their regimens, (2) barriers to medicationtaking, (3) properties of medications that could make them difficult to take and (4) what would make medications easier to take.

\section{METHODS}

\section{Participants}

A purposive sample was recruited through flyers, a platform of participants interested in research, and clinician referral from Mass General Brigham (MGB) health centres, in and around Boston, Massachusetts, USA. We were specifically interested in participants who may have deep knowledge about the potential issues. Specifically, participants were eligible if they were $\geq 18$ years of age, taking $\geq 2$ prescribed medications for diabetes, hypertension or hyperlipidaemia, and reported some non-adherence based on a validated self-reported adherence questionnaire (ie, $\geq 1$ dose missed in the last 30 days). ${ }^{23} 24$ We focused on these chronic cardiometabolic diseases because they are very common, interrelated, largely asymptomatic and often precursors to other conditions. ${ }^{25}$ Recruitment and interviewing occurred between April and December 2019.

Informed consent was obtained from all participants, and they received a US $\$ 50$ honorarium at interview completion. In this manuscript, we follow standards for reporting qualitative research, ${ }^{27} 28$ and participants are referred to by their study ID to preserve anonymity.

\section{Interviews}

We used semistructured interviews to elicit personal accounts and generate a deeper understanding of perceptions of medication use and behavioural impacts. JCL and NKC developed a comprehensive semistructured interview guide organised around separate but overlapping topics based on study objectives, their extensive research experience in adherence, gaps in prior literature: (1) how patients are using their medications and managing their regimens, (2) barriers to medication-taking, (3) discussions about properties of medications that could make them difficult to take and (4) what would make medications easier to take. The guide did not explicitly ask about mental health, a factor for non-adherence, ${ }^{29}$ to facilitate comfort with the interviewer. The interview guide was finalised after input from the multidisciplinary study team, which includes individuals with experience in qualitative research methods (online supplemental appendix table 1). The guide was pilot-tested with two non-participant volunteers, which resulted in only a few wording changes.
Interviews were conducted in-person with eligible patients at private conference or office rooms at Brigham and Women's Hospital, with only the interviewer present. Patients were all invited to attend those locations specifically but had been to the hospital before. All interviews were conducted by a trained interviewer and practising pharmacist (JCL) in English. Several strategies were used to mitigate any misperceptions about the nature of the interview, including meeting in non-clinic locations, wearing non-clinical outfits, emphasising that the encounter is not part of clinical care and that the interviewer is primarily a researcher and not part of their care team. ${ }^{30}$ The interviewer also had no prior or ongoing relationship with any participant and does not practically clinically where the patients were recruited from.

At the beginning of the interview, participants were also asked to complete a baseline demographic/clinical questionnaire. A sequential study ID was assigned to each interview. We continued conducting interviews until saturation was reached, defined by similar types of experiences being described without new emerging data. ${ }^{31} 32$ Saturation was reached by patient 24 and reaffirmed in the subsequent 2 interviews which had already been scheduled. Each interview lasted between $30-75 \mathrm{~min}$ (mean: 45).

\section{Data analyses}

The audiorecorded interviews were transcribed verbatim. Transcripts were checked for accuracy against the recordings. We used paper-based methods for initial stages of analysis. Two investigators annotated a selection of transcripts independently and devised preliminary codes; after discussion, preliminary codes were revised and agreed on, and major themes were identified. Analysis was conducted in parallel with additional interviews to determine saturation. Dedoose software V.8.3.10 (Los Angeles, California, USAA: SocioCultural Research Consultants) was used for storage, handling and analysis.

We used the immersion/crystallisation method to conduct the analysis. ${ }^{33} 34$ In this approach, we immersed ourselves in the collected data and then articulated the salient themes during the crystallisation process. We continued this method of cycles of concentrated textual review until all data were examined, and meaningful patterns emerged from the data. Early broad themes were clear, such as the nature of routine or disruptions to routines as barriers to medication-taking. All transcripts were then reread as additional themes emerged. Representative quotations were chosen to illustrate the themes; statements made by participants are shown in italics. Two participants reviewed their transcripts and findings for consistency, without any comment.

\section{Patient and public involvement}

Two patients were involved in pilot testing the interview guide and refining content. Two participants also checked transcript accuracy. 


\begin{tabular}{|c|c|c|}
\hline $\begin{array}{l}\text { Participant } \\
\text { identifier }\end{array}$ & Age (years) & Chronic condition of interest \\
\hline P1 & 62 & Diabetes, hyperlipidaemia \\
\hline P2 & 36 & Diabetes \\
\hline P3 & 52 & $\begin{array}{l}\text { Diabetes, hyperlipidaemia, } \\
\text { hypertension }\end{array}$ \\
\hline P4 & 70 & Diabetes, hyperlipidaemia \\
\hline P5 & 66 & $\begin{array}{l}\text { Diabetes, hyperlipidaemia, } \\
\text { hypertension }\end{array}$ \\
\hline P6 & 84 & Hypertension, hyperlipidaemia \\
\hline P7 & 62 & $\begin{array}{l}\text { Diabetes, hyperlipidaemia, } \\
\text { hypertension }\end{array}$ \\
\hline P8 & 31 & Diabetes \\
\hline P9 & 45 & Diabetes, hypertension \\
\hline P10 & 65 & $\begin{array}{l}\text { Diabetes, hyperlipidaemia, } \\
\text { hypertension }\end{array}$ \\
\hline P11 & 61 & $\begin{array}{l}\text { Diabetes, hyperlipidaemia, } \\
\text { hypertension }\end{array}$ \\
\hline P12 & 24 & Diabetes, hypertension \\
\hline P13 & 22 & Diabetes \\
\hline P14 & 58 & Hypertension \\
\hline P15 & 20 & Hypertension \\
\hline P16 & 70 & Diabetes \\
\hline P17 & 57 & Diabetes, hypertension \\
\hline P18 & 55 & Diabetes, hyperlipidaemia \\
\hline P19 & 44 & Hyperlipidaemia, hypertension \\
\hline P20 & 73 & Hyperlipidaemia, hypertension \\
\hline P21 & 43 & Diabetes, hypertension \\
\hline P22 & 76 & $\begin{array}{l}\text { Diabetes, hyperlipidaemia, } \\
\text { hypertension }\end{array}$ \\
\hline P23 & 40 & $\begin{array}{l}\text { Diabetes, hyperlipidaemia, } \\
\text { hypertension }\end{array}$ \\
\hline P24 & 58 & Hyperlipidaemia, hypertension \\
\hline P25 & $>89$ & Hyperlipidaemia, hypertension \\
\hline P26 & 74 & Hyperlipidaemia, hypertension \\
\hline
\end{tabular}

\section{RESULTS}

We conducted interviews with 26 participants (table 1); $54 \%$ were male, $65 \%$ were $<65$ years of age and $62 \%$ were white (online supplemental appendix table 2).

Participants spoke in great depth about barriers to medication-taking and their personal strategies for coping with their medication regimens. From these interviews, we identified six key themes around inconvenience, negative implications, deviations, property barriers to adherence, learnt coping strategies and ideal experiences (table 2). These themes are described in more detail below with representative transcript quotations.

\section{Medication-taking viewed as a highly inconvenient action}

Participants expressed feelings of annoyance about having to take medication and the struggle to constantly pay attention to their medications and their regimen regardless of whether they had been recently diagnosed. These feelings persisted even when directly queried about whether there were aspects of medication-taking that they liked.

P2: You're waiting around to take them; in a way you're binded by it.

P23: I take half of the 28 in the morning before I leave. I have to struggle, so I have to give myself time just to-before I leave and take all those medications.

P14: You have to learn the regimen-what time do I fit it into my day?

Others described that distractions disrupted their ability to remember because the medications were inconvenient.

P24: There's always something else that's coming up and distracting me from taking the meds. Anything that throws me off my routine leads to me having a tendency to forget.

P4: If I'm out and about, which is usually, I'll forget to take my midday medication. I have to be obsessed with makin' sure I take them.

Participants referred to medication use repeatedly as a 'process' that affected aspects of how they live their lives and something that they struggle to remember to do.

P8: The hardest part is the whole process. Sometimes I just forget. Maybe I'm really hungry or if I'm making dinner at home and I'm serving everybody, I realized halfway through my meal, 'Oops, I forgot.

\section{Negative implications because of inconvenience or illness perceptions}

Participants questioned why they were taking medications and expressed dismay about potentially needing to take medications for their entire life.

P1: It's not time consuming but just to take them all the time that's a battle. For a long time. I wish I kind of had a timeline to see if there's an end in sight, otherwise you just keep taking them and taking them and don't get to give up.

They described conflicting feelings between the desire to make lifestyle modifications and "laziness" from relying on medication use to improve their health.

P16: This is like a Band-Aid trying to prevent damage; eventually, the dosage you'll have increases and then you'll move on to insulin. You advance.

P21: I might stop taking the meds again and just go ahead and just try to do it cold turkey.

Single participants wondered aloud about why they bother to take medications given that they do not need to support other people.

P18: I'm single. I don't have kids. If I die, at least I don't have responsibilities, but I still take my medication anyway. You know, sometimes I wonder why I take it. 
Table 2 Summary of key themes

\begin{tabular}{|c|c|}
\hline Theme & Key takeaways \\
\hline (1) Medication-taking viewed as a highly inconvenient action & $\begin{array}{l}\text { Annoyance at and struggling to take medications } \\
\text { Medication-taking is viewed as a process }\end{array}$ \\
\hline $\begin{array}{l}\text { (3) Actual regimens can deviate substantially from prescribed } \\
\text { regimens }\end{array}$ & $\begin{array}{l}\text { Combining doses intended to be at separate times } \\
\text { Taking medications later than prescribed } \\
\text { Taking additional medications to counteract lifestyle } \\
\text { Forgetting to take doses altogether }\end{array}$ \\
\hline $\begin{array}{l}\text { (4) Certain medication properties may contribute to } \\
\text { adherence deviations }\end{array}$ & $\begin{array}{l}\text { Size of medications (too large or too small) } \\
\text { Smell or taste are detractors } \\
\text { Colour of medications in combination with others }\end{array}$ \\
\hline $\begin{array}{l}\text { (5) Development of numerous coping strategies to overcome } \\
\text { barriers }\end{array}$ & $\begin{array}{l}\text { Relying on colours or imprints for pill identification } \\
\text { Planning extra time to take medications } \\
\text { Creating 'cues' to take medications } \\
\text { Leveraging low-tech ways of transporting doses }\end{array}$ \\
\hline
\end{tabular}

Participants also expressed concerns about stigma from others about their condition. They described embarrassment, which often precluded the desire to involve friends or family in their daily routine. These perspectives manifested in overall negative individual impressions about their disease and medications.

P12: It doesn't feel like a death sentence, but almost there's kind of a stigma to it. The thought of not being as healthy as I wanted to be. It was pretty upsetting. Accepting it was hard.... Even the pill bottle, it's huge walking around with. My sister saw it. She's, like, 'Holy crap. That's the biggest pill bottle I've ever seen.'

P13: Sometimes if I go on vacation or on a trip, it's almost a bit weird. Maybe that stigma thing, like, "Oh, I'll be right back. I'm gonna go take my meds." My family knows, but I don't think a lotta my friends know. Almost like an embarrassment.

\section{Actual medication regimens can deviate substantially from prescribed regimens}

When asked to describe a typical day in how they take their medicines, participants described a wide variety of behaviours and often admitted that the way they take their medications is not fully as intended. Often these differences were relatively minor, such as forgetting to take doses, or taking medications all at once instead of separating them out throughout the day.

P10: One thing I started doing different was that the Metformin it said take 500[mg] twice a daily. I take $1000[\mathrm{mg}]$ at bedtime.
P15: Even if I wasn't supposed to take it at night, I take a lot of my medicines at night, because if I'm supposed to take them in the morning, I never ever remember.

Other routines were markedly different, such as taking extra, unprescribed medication doses.

P17: I have this little bottle with me, so if I'm going to a restaurant and all of a sudden I want that cheesecake I got extra Metformin in here so I can take it. I call them my rescue Metformins.

Even though participants acknowledged that they knew they were taking medications differently from prescribed, sometimes they did not recognise that they were in fact deviating, nor was it clear to them when it clinically mattered.

P21 shared that even if he 'misses it [medication] this time, I'll just take it later. As long as I take it within 24 hours, I should be good.'

\section{Certain medication properties may contribute to adherence deviations}

Participants characterised several medication properties as potential barriers. One of the most commonly described was medication size. The large size of some medications made swallowing more difficult and therefore required more effort to consume.

P8: I'm taking four pills of which one or two are large. It's not unusual to choke on one of those large pills.

P11: Some of them seem to be larger pills. They take up almost the entire P.M. [evening] container so that gets a little filling. Sometimes I'm like 'Well, dessert! 
P1: It's a big pill, and it feels like it sometimes gets stuck in my throat even when I drink with it. I would rather take smaller ones more times a day honestly than that one twice a day. That's how much I dislike the shape and size of that pill.

For others, medication size affected their ability to manage their medications in pillboxes, as either the medications were too large for conventional pillboxes or too small and were difficult to handle. Related to the inconvenience theme, larger sizes may lead to even more social stigma because they were more difficult to transport and use covertly.

P24 noted, One of my problems for missing my medications is the size of the pills that I'm on. If two of those are side by side in my pill container they get stuck in the little slot. If they get stuck and I don't think to count, then pills stay behind.

P4: The biggest problem I had was get-
ting them into the pillbox I bought.

P10: Sometimes my medication can even stay in my box. It's just small. It's nondescript. If you drop it and it bounces on the bathroom floor, and you're like, 'Oh, my god, I'll never find it'.

Beyond medication size, participants noted other properties of medications like the smell or taste as things that irritated them.

P1: If you don't get that medication down straight if that dissolves in your mouth that's awful.

P12: They kinda have a funky smell, when I smell them I associate it with-like, that's gross.

Medication colour rarely bothered participantsexcept in combination with other medications. Participants complained when their medications had a similar appearance as this makes it more difficult to tell them apart and know which medications they have taken that day or when they are filling their pillboxes. This may have exacerbated the underlying forgetfulness barriers that participants were experiencing.

P4: I certainly don't want the pills to all look the same because then I can't tell whether I'm taking the right ones. They should all look different.

P8: One thing that's super-frustrating to me is pills that are all white and the same shape. With my memory issues, I have to keep looking up, is this the right pill? 'Cause there are times also where I haven't filled the box properly.

P24 described an experience where giving a friend the wrong medication because they looked the same, 'I gave him a couple of those medications [lovastatin] because I put them in Ziploc bags and I thought it's blue; it's obviously Advil.
Development of numerous coping strategies to overcome barriers

Participants described a number of different ways to make their medications easier to reconcile and take. Some relied on their colours or imprints as ways to distinguish medications.

P17: I'm mad because my medications all look alike. I can't read the stupid little numbers. I'll take a watercolor magic marker, and I'll put blue on all the ibuprofens and green on the Metformin's, so I can just instantly know I'm not taking the wrong white oval pill.

Others noted the need to space out their medications and plan extra time to take them.

P23: It's not that I don't take my medication. It's that it gets stuck here. It could go to 15 minutes to get it down. I just have to always have at least a couple glasses of water just to take all my medications. If not, then I struggle. If I did all at once, then it would take me 3 hours to take all 28 medications.

Some of these coping strategies may also themselves contribute to adherence and regimen deviations, particularly when spacing from meals or other medications.

P3: I don't take both of them at same time, especially metformin. Don't want to chew that too big stuff.

Others described strategies such as creating 'cues' for themselves to know whether they took their medications. These included low-tech ways to take medications with them throughout the day, such as extra pillboxes, small bags, and using clothing pockets to enhance portability.

P15: I will genuinely think that I didn't take them and take another dose, so I turn my bottle upside down to remember if I took them.

P9: The metformin I need to eat with food, and so I tend to put two pills in my pocket and sometimes I forget to take them out of my pocket. Sometimes I'll go into my pants to get the medicine out and rather than there being two pills, there's three of them, because I forgot to take the pill previously.

P7: I used to have to take a noontime pill a lot when I worked, so I always stuck it in my pocket, so I always had it. Now I don't work, and I forget to put it in my pocket.

Sometimes, these strategies needed continual revision as their schedules changed.

P24: We have a white counter and I have a white pillbox. I was still forgetting, so I decided to put blue painter's tape on it so that as I walked by I got the contrasting color.

\section{Suggestions to make medication-taking easier}

Participants also expressed ideas about what their ideal medication-taking experience would be. They advocated for simpler medication regimens that would help them adhere, such as once-daily or once-weekly regimens. 
P15: I'd just like to be able to take my pills just all at the same time.

P12: Ideally, the less the better, the less frequent the more important it is to you, so the higher the priority it takes. 'Cause 'Oh, if you miss it this week, you're gonna have to go a week without it.'

Expense of medications was also a key issue for participants and noted as a way to make medication-taking easier.

P7: The cost is just too high. I think it is ridiculous that the cost of that medication is like over $\$ 600$ a month. It shouldn't be that way.

P19: I've spent a lot of money in the past on medications. I don't even like to think about it, because it's my health, but they are a big part of my life.

Participants suggested different medication colours, imprints and pill bottle markings as distinguishing features in their appearance that would make medicationtaking easier.

P8: Since I've already fallen twice, it helps to have different color pills in different shapes. I'm always so happy when I get a pill that's, like, a green oval shape!

P6: A big picture on the bottle, about the pill what it's like with the markings so that you don't make mistakes.

P10: If they had a little letter-like Levothyroxine had LEV on it. There's number codes on 'em, but for us, that code means absolutely nothing.

Finally, participants also expressed related ideas about creating chewable or liquid versions or adding coatings that would improve palatability and make their medication-taking routine easier.

P7: Gummy bears. It doesn't matter what they look like as long as I can swallow 'em.

P14: Do it in liquid with a flavor. Everybody from 9 years old to 99 knows how to hold a glass and drink it.

P20: I mainly wish some pills were coated better. It would slide down easier.

\section{DISCUSSION}

In this qualitative interview study of adults with nonadherence to medications for hypertension, diabetes and hyperlipidaemia, we observed six key themes around medication-taking, including inconvenience, negative implications, regimen deviations, medication properties, coping strategies and suggestions for improving medication-taking. Overall, these contemporary patients' experiences reinforce that many patients find medication-taking undesirable and associate it with negative connotations. Moreover, patients often take medications differently than prescribed, which could be in part due to properties of medications themselves or coping strategies that they have developed to overcome negative medication-related experiences.

Patients' underlying perceptions of medicationtaking may be shaped by illness connotations or inconvenience of medication-taking, indirectly leading to barriers, such as the tendency to forget doses. ${ }^{102235}$ Prior research has suggested that difficulty remembering to take medications could be related to not believing that they are important to take and thereby not purposefully integrating medication-taking into daily routines. ${ }^{22} 36$ Further, prior work has shown that patients with diabetes view medication-taking more negatively than either diet or exercise. ${ }^{37}$ This undesirability may be affected by the presence of other comorbidities, such as depression, and whether patients are already used to taking medication. ${ }^{38}$ Correspondingly, our research tracks with these prior findings by suggesting that non-adherent patients could be amplifying barriers to adherence by viewing medication-taking negatively, ultimately affecting their coping strategies.

These findings combined with literature insights have several important implications for clinical care and interventions. First, recognising and addressing potential negative perceptions around medication-taking may be critical to enhancing adherence. Providers view medications differently than patients and therefore may need to directly address and reframe illness perceptions with patients. ${ }^{16}$ Second, most patient education aimed at addressing adherence invokes negative framing, that is, motivating patients by focusing on how they reduce the risks of poor clinical outcomes. ${ }^{139}$ Research has found that other types of framing, such as positive framing or framing focusing on social rather than physical consequences, may ultimately be more effective. ${ }^{40} 41$ Third, providers may need to communicate more clearly what regimen deviations are acceptable for patients as they develop medication coping strategies. Here, participants described a variety of differences from what was prescribed; clarifying for patients which deviations may be clinically insignificant may help improve their experience.

While this research also suggests that medication properties may also affect patient experience, clinicians are frequently unaware of these difficulties and therefore cannot act on them. ${ }^{35}{ }^{36}$ For instance, decision support tools could be built into electronic health record systems that better incorporate information about dispensed medications. Even in the absence of point-of-care information, asking patients directly may improve their care, ${ }^{3542}$ as simplifying regimens, by reducing dosing frequency or number of separate, free-form medications may be possible and can improve adherence. ${ }^{2} 1020$ Depending on needs, patients also could potentially be prescribed alternative medications that may be easier for them to take. Community pharmacies could also be engaged in these activities by improving the packaging of dispensed medications and reduce confusion. ${ }^{43}$

This research also suggests that other healthcare actors, such as government, payers or manufacturers, 
could improve medication-taking for patients. Out-ofpocket medication costs are top of mind, as has been well-elucidated in prior work and is a national policy topic. $^{42} 4445$ Consistency in medication appearance has also been shown to affect adherence. ${ }^{46}$ Correspondingly, this research suggests that manufacturer modifications to enhance appearance and palatability could also improve patients' medication-taking experience. Even the currently published manufacturer patient-centred pharmaceutical design principles may be insufficient to address needs. ${ }^{47}{ }^{48}$ Reconciling these issues may become more important as patients use more medications to reach guideline targets; for example, $>80 \%$ of patients have regimens that could be intensified in hypertension alone. $^{49}$

\section{Limitations}

We deliberately selected participants who had some evidence of non-adherence to medications to better understand challenges in medication-taking; bias was mitigated by emphasising that no information would be passed to their usual care team about non-adherence and the interview guide included questions about both positive and negative experiences of using medications. Because the interviews were conducted in-person, response bias may have been possible, in that participants may have wanted to appear as having more self-efficacy; however, having restricted to those who self-reported nonadherence could actually have mitigated this concern. We expect no major impacts on the dependability of the data, but this study was also conducted in one geographical location and could differ slightly across chronic conditions. Despite numerous mitigation factors for patients' perceiving the interview in a clinical nature, this nevertheless could have affected credibility the findings.

\section{CONCLUSION}

Patients often find medication-taking highly undesirable and take medications differently than prescribed, which could be in part due to the properties of medications themselves or as a consequence of coping strategies that they have developed. Interventions that reduce inconvenience and tailor medications to individual needs may markedly improve medication-taking and adherence.

\footnotetext{
Author affiliations

${ }^{1}$ Division of Pharmacoepidemiology and Pharmacoeconomics, Department of Medicine, Brigham and Women's Hospital and Harvard Medical School, Boston, Massachusetts, USA

${ }^{2}$ Center for Healthcare Delivery Sciences, Brigham and Women's Hospital, Boston, MA, USA

${ }^{3}$ Division of Endocrinology, Diabetes and Hypertension, Department of Medicine, Brigham and Women's Hospital, Boston, Massachusetts, USA

${ }^{4}$ Division of Rheumatology, Immunology and Allergy, Department of Medicine, Brigham and Women's Hospital, Boston, Massachusetts, USA

${ }^{5}$ Division of Cardiovascular Medicine, Department of Medicine, Brigham and Women's Hospital, Boston, Massachusetts, USA

${ }^{6}$ Division of Preventive Medicine, Department of Medicine, Brigham and Women's Hospital, Boston, Massachusetts, USA
}

Twitter Julie C Lauffenburger @jlauffen and Daniel H Solomon @DanielHSolomon

Contributors JCL planned, conducted, reported and designed the interviews, interpreted the data, drafted the manuscript and contributed to conceptualising and designing the study. NH contributed to planning, conception and design, including code and theme development (ie, interpretation of the data), and critically revised the manuscript. MM, DHS, EA and RJG contributed to conceptualising and designing the study and critically revised the manuscript for intellectual content. NC contributed to conceptualising and designing the study interview guide development, theme development and critically revised the manuscript. All authors approved the final manuscript. JCL is the guarantor and responsible for the overall content.

Funding This research was supported by a career development grant from the $\mathrm{NIH}$ National Heart, Lung, and Blood Institute (NHLBI) to BWH (JCL) (K01 HL 141538).

Disclaimer The content is solely the responsibility of the authors and does not necessarily represent the official views of the $\mathrm{NIH}$.

Competing interests RJG reports unrestricted research funding from AstraZeneca, Kowa, Novartis and Pfizer for unrelated work. NKC is a consultant to and holds equity in RxAnte, unrelated to this work. He receives grant funding, payable to his institution, from Boehringer Ingelheim and Humana, also unrelated to the current work. DHS receives salary support from research contracts to Brigham and Women's Hospital from Abbvie, Amgen, Corrona, Genentech and Janssen.

Patient consent for publication Not applicable.

Ethics approval The MGB Institutional Review Board approved the study (Number: 2017P002657).

Provenance and peer review Not commissioned; externally peer reviewed.

Data availability statement Data are available on reasonable request. Data are available upon reasonable request, pending appropriate agreements and Institutional Review Board approval.

Supplemental material This content has been supplied by the author(s). It has not been vetted by BMJ Publishing Group Limited (BMJ) and may not have been peer-reviewed. Any opinions or recommendations discussed are solely those of the author(s) and are not endorsed by BMJ. BMJ disclaims all liability and responsibility arising from any reliance placed on the content. Where the content includes any translated material, BMJ does not warrant the accuracy and reliability of the translations (including but not limited to local regulations, clinical guidelines, terminology, drug names and drug dosages), and is not responsible for any error and/or omissions arising from translation and adaptation or otherwise.

Open access This is an open access article distributed in accordance with the Creative Commons Attribution Non Commercial (CC BY-NC 4.0) license, which permits others to distribute, remix, adapt, build upon this work non-commercially, and license their derivative works on different terms, provided the original work is properly cited, appropriate credit is given, any changes made indicated, and the use is non-commercial. See: http://creativecommons.org/licenses/by-nc/4.0/.

\section{ORCID iDs}

Julie C Lauffenburger http://orcid.org/0000-0002-4940-4140

Daniel H Solomon http://orcid.org/0000-0001-8202-5428

\section{REFERENCES}

1 Sokol MC, McGuigan KA, Verbrugge RR, et al. Impact of medication adherence on hospitalization risk and healthcare cost. Med Care 2005;43:521-30.

2 Osterberg L, Blaschke T. Adherence to medication. N Engl J Med 2005;353:487-97.

3 Bitton A, Choudhry NK, Matlin OS, et al. The impact of medication adherence on coronary artery disease costs and outcomes: a systematic review. Am J Med 2013;126:e327:357 e357-357.e27.

4 Wang B, Choudhry NK, Gagne JJ, et al. Availability and utilization of cardiovascular fixed-dose combination drugs in the United States. Am Heart J 2015;169:e371:379-86.

5 Lauffenburger JC, Robinson JG, Oramasionwu C, et al. Racial/Ethnic and gender gaps in the use of and adherence to evidence-based preventive therapies among elderly Medicare Part $D$ beneficiaries after acute myocardial infarction. Circulation 2014;129:754-63.

6 Yeaw J, Benner JS, Walt JG, et al. Comparing adherence and persistence across 6 chronic medication classes. J Manag Care Pharm 2009;15:728-40. 
7 luga AO, McGuire MJ. Adherence and health care costs. Risk Manag Healthc Policy 2014;7:35-44.

8 Johnson FR, Ozdemir S, Manjunath R, et al. Factors that affect adherence to bipolar disorder treatments: a stated-preference approach. Med Care 2007;45:545-52.

9 Cutrona SL, Choudhry NK, Fischer MA, et al. Targeting cardiovascular medication adherence interventions. J Am Pharm Assoc 2012;52:381-97.

10 Gellad WF, Grenard JL, Marcum ZA. A systematic review of barriers to medication adherence in the elderly: looking beyond cost and regimen complexity. Am J Geriatr Pharmacother 2011;9:11-23.

11 Sanfélix-Gimeno G, Franklin JM, Shrank WH, et al. Did HEDIS get it right? evaluating the quality of a quality measure: adherence to $\beta$-blockers and cardiovascular outcomes after myocardial infarction. Med Care 2014;52:669-76.

12 Zullig LL, Peterson ED, Bosworth HB. Ingredients of successful interventions to improve medication adherence. JAMA 2013;310:2611-2.

13 Viswanathan M, Golin CE, Jones CD, et al. Interventions to improve adherence to self-administered medications for chronic diseases in the United States: a systematic review. Ann Intern Med 2012;157:785-95.

14 Fields J, Go JT, Schulze KS. Pill properties that cause dysphagia and treatment failure. Curr Ther Res Clin Exp 2015;77:79-82.

15 Gonzalez JS, Tanenbaum ML, Commissariat PV. Psychosocial factors in medication adherence and diabetes self-management: implications for research and practice. Am Psychol 2016;71:539-51.

16 Broadbent E, Donkin L, Stroh JC. Illness and treatment perceptions are associated with adherence to medications, diet, and exercise in diabetic patients. Diabetes Care 2011;34:338-40.

17 Shrank WH, Liberman JN, Fischer MA, et al. Physician perceptions about generic drugs. Ann Pharmacother 2011;45:31-8.

18 Cutrona SL, Choudhry NK, Fischer MA, et al. Modes of delivery for interventions to improve cardiovascular medication adherence. Am J Manag Care 2010;16:929-42.

19 Calvert SB, Kramer JM, Anstrom KJ, et al. Patient-Focused intervention to improve long-term adherence to evidence-based medications: a randomized trial. Am Heart J 2012;163:e651:65 7-665-65.

20 Lauffenburger JC, Landon JE, Fischer MA. Effect of combination therapy on adherence among US patients initiating therapy for hypertension: a cohort study. J Gen Intern Med 2017;32:619-25.

21 SPRINT Research Group, Wright JT, Williamson JD, et al. A randomized trial of intensive versus standard blood-pressure control. N Engl J Med 2015;373:2103-16.

22 Lauffenburger JC, Isaac T, Bhattacharya R, et al. Prevalence and impact of having multiple barriers to medication adherence in nonadherent patients with poorly controlled cardiometabolic disease. Am J Cardiol 2020;125:376-82.

23 Wilson IB, Lee Y, Michaud J, et al. Validation of a new ThreeItem self-report measure for medication adherence. AIDS Behav 2016;20:2700-8.

24 Lauffenburger JC, Fontanet CP, Isaac T, et al. Comparison of a new 3-item self-reported measure of adherence to medication with pharmacy claims data in patients with cardiometabolic disease. Am Heart J 2020;228:36-43.

25 Sakakibara BM, Obembe AO, Eng JJ. The prevalence of cardiometabolic multimorbidity and its association with physical activity, diet, and stress in Canada: evidence from a populationbased cross-sectional study. BMC Public Health 2019;19:1361.

26 Shah NS, Lloyd-Jones DM, O'Flaherty M, et al. Trends in cardiometabolic mortality in the United States, 1999-2017. JAMA 2019;322:780-2.

27 Tong A, Sainsbury P, Craig J. Consolidated criteria for reporting qualitative research (COREQ): a 32-item checklist for interviews and focus groups. Int J Qual Health Care 2007;19:349-57.
28 O'Brien BC, Harris IB, Beckman TJ, et al. Standards for reporting qualitative research: a synthesis of recommendations. Acad Med 2014;89:1245-51.

29 Grenard JL, Munjas BA, Adams JL, et al. Depression and medication adherence in the treatment of chronic diseases in the United States: a meta-analysis. J Gen Intern Med 2011;26:1175-82.

30 Rathbone AP, Jamie K. Transferring from clinical pharmacy practice to qualitative research: questioning identity, Epistemology and ethical frameworks. Sociol Res Online 2016;21:1-9.

31 Saunders B, Sim J, Kingstone T, et al. Saturation in qualitative research: exploring its conceptualization and operationalization. Qual Quant 2018;52:1893-907.

32 Rathbone AP, Jamie K, Todd A, et al. A qualitative study exploring the lived experience of medication use in different disease states: linking experiences of disease symptoms to medication adherence. $J$ Clin Pharm Ther 2021;46:352-62.

33 Reis S, Biderman A, Mitki R, et al. Secrets in primary care: a qualitative exploration and conceptual model. J Gen Intern Med 2007;22:1246-53.

34 Borkan JM. Crystallization-immersion. Sage Publications, 1999.

35 Lee S, Bae YH, Worley M, et al. Validating the modified drug adherence work-up (M-DRAW) tool to identify and address barriers to medication adherence. Pharmacy 2017;5. doi:10.3390/ pharmacy5030052. [Epub ahead of print: 08 Sep 2017].

36 Calabrese EJ. Converging concepts: adaptive response, preconditioning, and the Yerkes-Dodson law are manifestations of hormesis. Ageing Res Rev 2008;7:8-20.

37 Huang ES, Brown SES, Ewigman BG, et al. Patient perceptions of quality of life with diabetes-related complications and treatments. Diabetes Care 2007;30:2478-83.

38 Anthony $\mathrm{H}$, Valinsky L, Inbar Z, et al. Perceptions of hypertension treatment among patients with and without diabetes. BMC Fam Pract 2012;13:24.

39 Conn VS, Ruppar TM. Medication adherence outcomes of 771 intervention trials: systematic review and meta-analysis. Prev Med 2017;99:269-76.

40 Keller PA. Designing effective health communications: a meta analysis of experimental results. Journal of Macromarketing 2008;29:279-302.

41 Affect KPA. Framing, and Persuasian. Journal of Marketing Research 2003;40:54-64.

42 Choudhry NK, Denberg TD, Qaseem A, et al. Improving adherence to therapy and clinical outcomes while containing costs: opportunities from the greater use of generic medications: best practice advice from the clinical guidelines Committee of the American College of physicians. Ann Intern Med 2016;164:41-9.

43 Doucette WR, Farris KB, Youland KM, et al. Development of the drug adherence work-up (draw) tool. J Am Pharm Assoc 2012;52:e199-204

44 Lauffenburger JC, Farley JF, Gehi AK, et al. Factors driving anticoagulant selection in patients with atrial fibrillation in the United States. Am J Cardiol 2015;115:1095-101.

45 Trump promised seniors drug discount cards. They may be illegal 2020

46 Kesselheim AS, Bykov K, Avorn J, et al. Burden of changes in pill appearance for patients receiving generic cardiovascular medications after myocardial infarction: cohort and nested casecontrol studies. Ann Intern Med 2014;161:96-103.

47 Liu F, Ranmal S, Batchelor HK, et al. Patient-Centred pharmaceutical design to improve acceptability of medicines: similarities and differences in paediatric and geriatric populations. Drugs 2014;74:1871-89.

48 Hanning SM, Lopez FL, Wong ICK, et al. Patient centric formulations for paediatrics and geriatrics: similarities and differences. Int J Pharm 2016;512:355-9.

$49 \mathrm{Mu} \mathrm{L}$, Mukamal KJ. Treatment intensification for hypertension in US ambulatory medical care. J Am Heart Assoc 2016;5. doi:10.1161/ JAHA.116.004188. [Epub ahead of print: 2210 2016]. 